\title{
The Influencing Mechanism of Social Capital on the Identification of Entrepreneurial Opportunities for New Farmers
}

\author{
Hui Jia, Han Zhang*, Yang Yu, Dongyang Xu, Huan Wang \\ School of Economics and Management, Beijing Institute of Petrochemical Technology, Beijing, China \\ Email: ^1621885521@qq.com
}

How to cite this paper: Jia, H., Zhang, H., Yu, Y., Xu, D. Y., \& Wang, H. (2020). The Influencing Mechanism of Social Capital on the Identification of Entrepreneurial Opportunities for New Farmers. American Journal of Industrial and Business Management, 10, 1839-1852.

https://doi.org/10.4236/ajibm.2020.1012114

Received: October 26, 2020

Accepted: December 20, 2020

Published: December 23, 2020

Copyright $\odot 2020$ by author(s) and Scientific Research Publishing Inc. This work is licensed under the Creative Commons Attribution International License (CC BY 4.0).

http://creativecommons.org/licenses/by/4.0/ (c) (i) Open Access

\begin{abstract}
With the promotion of China's Rural Revitalization Strategic Planning, the number of rural people returning to the countryside to start their own businesses continues to grow. Accompanied by the return of entrepreneurs, there are also a large number of new farmers, such as cross-industry entrepreneurs, university students, migrant workers returning to their hometowns to start businesses and other new types of agricultural business operators. Entrepreneurship of new farmers is an important field for them to participate in rural practice, which helps to activate rural resource factors, foster new growth drivers, increase rural employment and income, and better implement the rural revitalization strategy. Social capital is an important resource that affects the heterogeneous information acquisition and entrepreneurial performance of new farmers, while opportunity identification is the starting point of entrepreneurial activities and runs through the whole entrepreneurial process. This paper tries to explore the theoretical influencing mechanism of social capital on the identification of entrepreneurial opportunities of new farmers, which is of positive significance to promote the innovation and entrepreneurship of new farmers, improve their entrepreneurial performance and even promote economic transformation.
\end{abstract}

\section{Keywords}

Social Capital, New Farmers, Entrepreneurial Opportunity, Identification

\section{Introduction}

In 2018, the central government of China issued a series of documents and plans on the rural revitalization strategy, forming a systematic strategic layout. In this 
strategic context, the number of rural people returning home to start their own businesses has been growing in recent years, reaching more than 7.8 million as of January 2019. Accompanied by the return of entrepreneurs, there are also a large number of new farmers, such as cross-industry entrepreneurs, university students, migrant workers returning to their hometowns to start businesses and other new types of agricultural business operators. Entrepreneurship of new farmers is an important field for them to participate in rural practice, which helps to activate rural resource factors, foster new growth drivers, increase rural employment and income, and better implement the rural revitalization strategy. However, there are still many difficulties and problems in the process of business start-ups, which, to a certain extent, inhibit their enthusiasm for starting a business. Social capital is an important resource that affects the heterogeneous information acquisition and entrepreneurial performance of new farmers, while opportunity identification is the starting point of entrepreneurial activities and runs through the whole entrepreneurial process. The research on social capital and the identification of new farmers' entrepreneurial opportunities is of great significance to explain the complex entrepreneurial phenomena, promote the innovation and entrepreneurship of new farmers, improve their entrepreneurial performance and even promote economic transformation.

\section{Literature Review}

\section{1) New Farmers}

Different from the traditional farmers, the new farmers are a new type of economic group. The research on this group in the theoretical circle is still in the initial stage, and there are few theoretical discussions. The new farmer is a new type of agricultural operating entity that is mainly engaged in agriculture-related production and operation and service provision under the background of the Internet (Yan \& Jiang, 2019). As for the composition of new farmers, one is the young migrant workers who grow up in rural areas and go out to work all the year round to keep up with the new era. After many years of work, they have gained certain wealth. They still yearn for returning to their hometown, so they set foot on the road of starting a business back home with new insights, funds and dreams. The second is that a small number of college graduates and highly educated intellectuals, with the ideal of changing the traditional farming methods and changing the appearance of the countryside, are tired of the noise and impetuousness of the city, and want to experience a rural life and build an ideal life by running farms and enterprises in the countryside. Thirdly, some successful entrepreneurs look forward to the development trend of China's economy. Seeing the development prospect of China's ecological agriculture, they take the initiative to go to the countryside to seek new economic growth points and start the farming industry. Zhang (2016) made a comprehensive analysis of the obstacles encountered in the current development of the background of new farmers and put forward the future policy direction to support the development of 
new farmers. Guo \& Tan (2016) analyzed the factors that influence the growth of new farmers, such as profit-driven food safety, personalized consumer demand, and agricultural producers' income needs, etc., and proposed the policy to promote the growth of new farmers. Yan \& Jiang (2018) analyzed the financing problems, risk control, insufficient effective assets and other problems in the process of new farmers' entrepreneurship, aiming to point out the direction for the coupled and coordinated development of rural finance and new farmers' entrepreneurship.

At present, there are many theoretical researches on farmer entrepreneurship, but few researches on new farmer entrepreneurship. As a new type of agricultural operating subject, it has its own unique characteristics, so it is of certain research value to study the problem of its entrepreneurship. With the continuous development of new farmers, the Chinese government and scholars began to pay attention to the entrepreneurship of new farmers. In order to solve the deep-seated crux of new farmers' entrepreneurial dilemma, it is urgent for the theoretical circle to conduct in-depth analysis and provide theoretical guidance for the success of new farmers' entrepreneurship.

\section{2) The Social Capital and Entrepreneurial Opportunity Identification}

Social capital is essentially a specific social network formed through interpersonal interaction and the potential social resources it brings. It is reflected in the relationship between people, and only becomes a kind of real capital when it is used and mobilized by actors. Social capital can be divided into homogeneous social capital and heterogeneous social capital according to its nature. Homogeneous social capital can be subdivided into family, clan, kin, local and emotional social capital, etc. Heterogeneous social capital is often constructed on the basis of modern legal factors, including colleague type, classmate type, comrade-in-arms type and interest type, and also formed on the basis of some public benefit purpose or industry interest purpose, such as social intermediary organizations, various trade associations and other legal type social capital.

For entrepreneurs or would-be makers, they need to master the basic logic of starting a business and accurately grasp the opportunity of starting a business. To capture entrepreneurial opportunities, it is necessary to accurately identify the connotation, source positioning, evaluation and the value of entrepreneurial opportunities, so as to achieve competitive business success. Tang (2020) started from the analysis of the connotation, characteristics and sources of entrepreneurial opportunities, and proposed a general method for identifying entrepreneurial opportunities. At the same time, he stressed that for entrepreneurs, when analyzing the factors affecting the identification and development of opportunities, attention should be paid to the natural attributes of opportunities and the individual attributes of entrepreneurs. Furthermore, entrepreneurs' understanding and identification of the source of entrepreneurial opportunities depends on the comprehensive effects of environmental factors, market trends, 
knowledge reserve, market control ability and other factors.

In order to explore the influence of social capital on entrepreneurial opportunity identification, many scholars have carried out quantitative research. According to Nahapiet \& Ghoshal (1998)'s social capital theory, Wang et al. (2017) introduced three variables, namely relational dimension, structural dimension and cognitive dimension, and explored the impact of social capital on the feasibility and profitability of opportunity identification through SEM model. The results showed that the three dimensions of social capital were positively correlated with feasibility and profitability. The research results of Shu (2012) indicate that cognitive trust positively regulates the relationship between weak connection and entrepreneurial opportunity identification. Guo \& Ding (2012) studied the relationship between social capital, prior knowledge and opportunity identification. The conclusion shows that the size of farmers' strong relationship network is significantly positively correlated with the amount of entrepreneurial opportunity identification. Gao et al. (2013), based on the strong and weak connection theory, divided social capital into three aspects: the degree of social capital's richness, the degree of strong association and the degree of weak association. Through research, they found that the size of the weak association network could help farmers improve the quality and efficiency of opportunity identification. Zhu (2013) found that the structural, relational and cognitive dimensions of social capital are positively correlated with five aspects of opportunity identification specific behaviors (business knowledge, collective behavior, forward-looking search, competitive review and innovation behavior). Zhou (2014) used binary logistic regression analysis method to analyze micro-enterprises in Chongqing and found that the family social capital of micro-enterprise entrepreneurs had a significant positive impact on the identification of entrepreneurial opportunities. Zhu \& $\mathrm{Hu}$ (2015) found in their study that the identification of entrepreneurial opportunities of returnees plays an intermediary role between social capital and entrepreneurial performance.

To sum up, concerning the influence of social capital on the identification of entrepreneurial opportunities, most studies adopt the theory of strong and weak connections with few studies being carried out on dividing social capital into three dimensions. Most of the existing quantitative research results are to find the correlation between the two, but there are few researches concentrating on the theoretical mechanism of social capital affecting the identification of entrepreneurial opportunity, especially those linking it with the new farmers. This paper tries to combine the three-dimensional social capital with the entrepreneurial opportunity identification process, and to explore the theoretical mechanism of social capital influencing the identification of entrepreneurial opportunities for new farmers, so as to promote the group to identify opportunities creatively, thus to capture business opportunities, integrate resources and build strategies for successful entrepreneurship. 


\section{The Entrepreneurial Opportunity Identification: Process and Capability Improvement Path}

The new farmer's entrepreneurship begins with his identification of entrepreneurial opportunities. The identification of entrepreneurial opportunity is a key issue in the field of entrepreneurship. Identifying entrepreneurial opportunities is a process of repeated thinking and exploration and transformation of creativity or innovation. It is a process of constant adjustment, repetition and balance. In this process, the potential expected value of the opportunity is repeatedly weighed against the entrepreneur's own ability, and the entrepreneur's strategic positioning of the entrepreneurial opportunity becomes increasingly clear, which is called the process of opportunity identification or opportunity development (Figure 1). Entrepreneurial opportunity identification is a process in which entrepreneurs perceive and identify entrepreneurial opportunities when relevant conditions are met.

\section{1) The Perception of Entrepreneurial Opportunities}

New farmers are agricultural practitioners with ecological awareness, and they are agricultural practitioners with ecological consciousness, caring for human beings, caring for the environment and protecting organisms in the agricultural industrial chain. They are also agricultural industry leaders with knowledge, understanding of operation, management, love of learning, use of science and technology, and respect for scientific rules. The identification of entrepreneurial opportunities for new farmers begins with the perception and discovery of entrepreneurial opportunities. As many entrepreneurial opportunities are not difficult to find, new farmers can make use of their previous special industrial experience (young migrant workers and some successful business owners) and

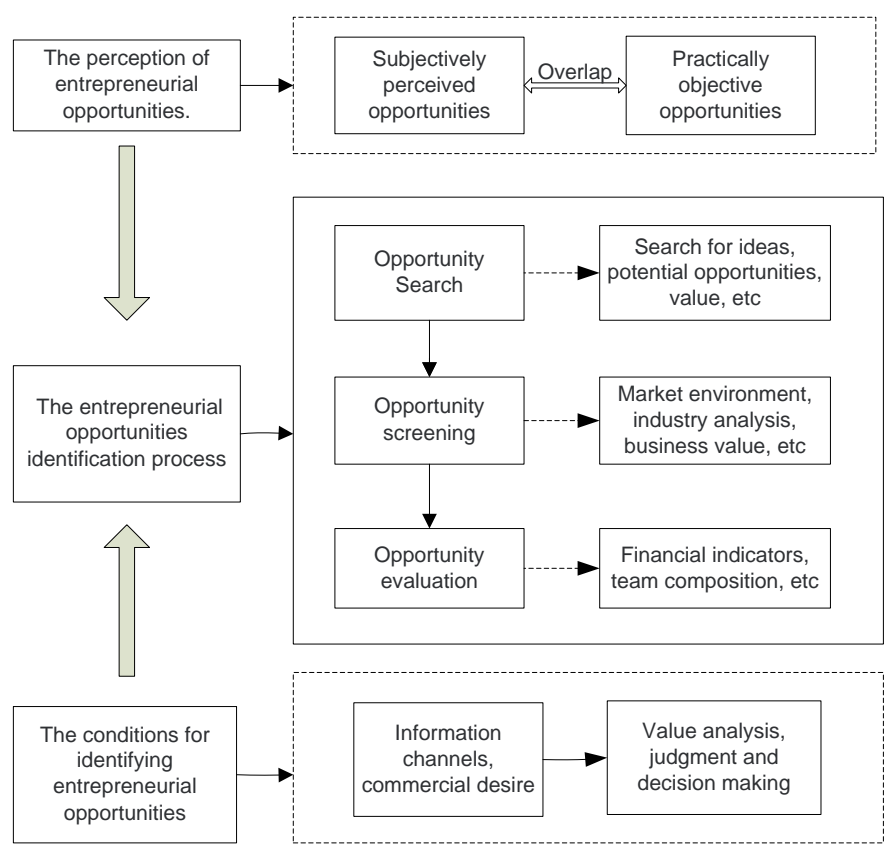

Figure 1. The entrepreneurial opportunities identification process. 
knowledge (college students) to perceive entrepreneurial opportunities, and actively search for opportunity logic, so as to form the overlapping of perceived subjective opportunities and actual objective opportunities. However, when the perceived subjective opportunity and the actual objective opportunity overlap relatively low, there will be uncertainty and risk of entrepreneurship.

\section{2) The Entrepreneurial Opportunities Identification Process}

Firstly, it is the opportunity search. New farmers search for possible ideas in the agricultural industry chain. If entrepreneurs realize that an idea may be a potential business opportunity and has potential development value, they will enter the next stage of opportunity identification. Secondly, it is the opportunity screening. Compared with the process of opportunity identification in the overall sense, the opportunity identification here should be the identification in the narrow sense, that is, screening the appropriate opportunities from the creativity. Whether the opportunity is a favorable business opportunity in a broad sense can be determined by analyzing the overall market environment, the rural industrial environment, and the general industry. At the same time, examine whether the opportunity is valuable to particular new farmers and investors. Finally, it is the opportunity evaluation. The main contents of the investigation are financial indicators, entrepreneurial team composition, etc., and new farmers decide whether to formally establish enterprises to attract investment through evaluation. In the initial stage of opportunity identification, the new farmer can informally survey the market's needs and determine the resources needed until the opportunity is deemed worthy of consideration or further development. At the later stage of opportunity development, this evaluation becomes more standardized and focuses on examining whether specific combinations of these resources can create sufficient commercial value in the agricultural industrial chain.

\section{3) The Conditions for Identifying Entrepreneurial Opportunities}

Firstly, new farmers need to be able to find value. That is, they have access to high-value information about the agricultural industry chain, which is often difficult for others to access. This is mainly understood in terms of access to information and the desire to start a business. Second, new farmers need to be able to analyze values. That is to analyze the value of business information and make accurate judgment and decision. Of course, the factors affecting the ability of information analysis include the intelligence structure and previous experience of the individual or team of the new farmer entrepreneur, the ability of innovative thinking, whether the new farmer entrepreneur has an optimistic attitude, whether the new farmer entrepreneur has keen insight, etc. Both of them are indispensable. If the value information can be found but cannot be analyzed, processed and applied, the obtained information will not generate commercial value. If the new farmer only has strong information analysis and processing capacity, and no source of valuable information, it is of no help as well.

Entrepreneurial opportunity is the core driving force of the entrepreneurial 
process, new farmers or work team is the leader of the entrepreneurial process, and resources are the necessary guarantee for the success of entrepreneurship. The entrepreneurial process begins with entrepreneurial opportunity, not money, strategy, network, team, or business plan. New farmers' ability to identify potentially valuable opportunities (Figure 2) is more important than capital, team talent and ability, and resources for adaptation. On the one hand, for new farmers with entrepreneurial intention (young migrant workers, some successful business owners and college students), previous work or internship positions, rich work and life experience, extensive social network, and individual initiative to seek opportunities all affect their accessibility to entrepreneurial opportunities. On the other hand, the knowledge reserve and practical skills of new farmers and their teams form their ability to use relevant information. These two aspects significantly affect the ability of new farmers to identify potential opportunities.

\section{The Theoretical Influencing Mechanism of Social Capital on Entrepreneurial Opportunity Identification}

New farmers take agriculture as their ideal of starting a business, possess scientific and cultural qualities, master modern agricultural production skills, and have certain management capabilities. They are "fashionable farmers" who take agricultural income as their source of livelihood. So they are a new breed of farmers who are literate, skilled and able to operate. The "new" of new farmers is mainly injected from the form of business, role and concept, that is, new form of business, new group and new cell. By cooperating with local village committees, they effectively integrate various rural resources to develop new agriculture, build new villages and share new life. Such a group of people with new ideas and new forms of business transferred to agricultural production and management, or directly engaged in agricultural production, or indirectly engaged in agricultural management, they are longing for their personal feelings for agriculture to obtain wealth through agricultural entrepreneurship.



Figure 2. The formation path of entrepreneurial opportunity identification ability. 
Social capital is an important resource that affects the heterogeneity of information acquisition and entrepreneurial performance of new farmers. Social capital is usually compared with human capital and financial capital, and it has an increasing influence on entrepreneurial activities, attracting the attention of entrepreneurial researchers and practitioners. Based on Nahapiet \& Ghoshal (1998)'s social capital theory, this paper analyzes the relationship, structure and cognitive dimensions of social capital. The relationship dimension of the social capital refers to the resources obtained by entrepreneurs through their relationship with other members of the social network, such as obligation, credit, trust, friendship, etc. Structural dimension refers to the structural characteristics of entrepreneur's social network, such as network size and network density. Cognitive dimension refers to the cognitive convergence of network members, such as mutual understanding, Shared language, Shared vision, etc. The perception and identification of entrepreneurial opportunities of new farmers need to form synergy in the cognitive, relational and structural dimensions of their social capital (Figure 3).

\section{1) The Relational Dimension}

New farmers have the characteristics of high human capital, they are highly educated, have certain expertise and skills, love agriculture, rural areas and have a sense of mission. The relationship circle of new farmers may be born in rural areas, or they may be born outside. They may be new farmers with modern consciousness, or they may be entrepreneurs, operators, business owners, white-collar workers and senior intellectuals in urban and rural areas. It can also be creative people of all kinds, eco-enthusiasts of nature and international people.

In the dimension of relationship, the social capital of new farmers mainly refers to: first, new farmers and social network can trust and cooperate sincerely; second, new farmers and social network contacts keep their promises; third, new farmers are closely connected with social network; fourth, social network often helps solve problems (Figure 4). The social network of new farmers has an important influence on their perception and identification of entrepreneurial opportunities. Entrepreneurial opportunities consist of discovered entrepreneurial opportunities and created entrepreneurial opportunities. The size of the new farmer entrepreneur's social network and the scope of "weak connections" restrict the entrepreneur's ability to identify or create entrepreneurial opportunities. The entrepreneur's social network includes government, financial institutions, universities, support organizations, business partners, friends, family, colleagues, etc. The social network of new farmer entrepreneurs can be divided into "strong connections" and "weak connections". Granovetter (1973) points out that the wide range of weak connections in the network is conducive to the acquisition of information and the discovery of entrepreneurial opportunities, while the "strong connections" are conducive to the acquisition of deep resources such as knowledge. The wide range of "weak connections" among potential entrepreneurs contributes to the availability of information and the discovery of entrepreneurial opportunities. "Strong connections" are based on trust 
and emotional connections, which can promote the effective transmission of information and enable entrepreneurs to better obtain information, so that it easier to turn the information into possible entrepreneurial opportunities. Despite its loose nature, lack of trust, or lack of emotional foundation, "weak connections" are more widely distributed than "strong connections" to serve as a bridge across individual social boundaries. It can go beyond the category of "strong connections" to obtain high-value information and related resources from different groups and networks. It can Expand new farmer entrepreneurs' information acquisition channels, enrich their information acquisition volume, and greatly enhance the identification possibility of entrepreneurial opportunities.

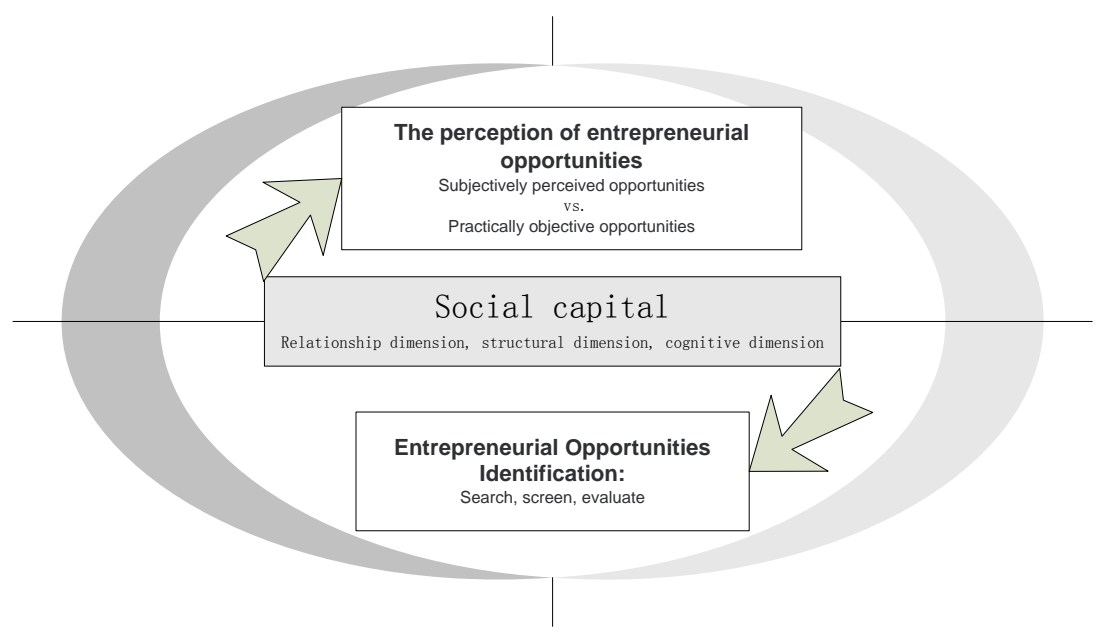

Figure 3. Three-dimensional social capital influencing the perception and identification of entrepreneurial opportunities.



Figure 4. Three dimensions of the social capital. 


\section{2) The Structural Dimension}

In terms of structural dimension, the social capital of new farmers mainly refers to: firstly, the number of relationships is large; secondly, many new relationships are obtained through existing relationships; thirdly, the information can be quickly obtained from the social network (Figure 4). The social network scale and network density of new farmers affect their entrepreneurial opportunity perception and identification. The emergence of network structure holes promotes the discovery of entrepreneurial opportunities for new farmers. In the agricultural industry chain, if a downstream network with potential demand and an upstream network with potential resources are not interconnected, there is a network structure hole. If the new farmer joins in the middle, he fills and monopolizes the structural hole. The more holes in the structure are filled by the network of new farmers, the more likely they are to find entrepreneurial opportunities. If the upstream has the resources that the downstream can use, or the downstream has the demand that the upstream resources can serve, the entrepreneur in the structure hole can realize and exclusively take advantage of this entrepreneurial opportunity. Social relation network is the main source for new farmers to identify entrepreneurial opportunities. The resource endowment of new farmers or their team will also affect their identification of entrepreneurial opportunities.

\section{3) The Cognitive Dimension}

New farmers are a group of people who can activate rural precipitation assets, excavate rural cultural and historical resources, introduce modern management concepts, and activate rural productivity. They started from the transformation of the traditional agricultural production mode, circulation mode and consumption mode, and then changed the agricultural industry ecology, they made efforts to make the agricultural industry from a backward industry into a competitive industry. At the same time, they create value for the introduction of five new industries in rural areas, namely ecological recycling industry, life service industry, health and health care industry, folk custom education industry and rural tourism industry.

First of all, new farmers' previous industrial special experience (young migrant workers, business owners, etc.) and knowledge (college students) affect the discovery and identification of entrepreneurial opportunities. Previous experience is one of the most important factors in determining one's cognitive ability and entrepreneurial skills, because most entrepreneurs' entrepreneurial ability is based on previous experience and continuously growing. New farmer entrepreneurs combine special knowledge of traditional and modern agriculture, especially knowledge of industrial environment, to find entrepreneurial opportunities in the same or related industries. Industrial environmental knowledge includes elements of upstream suppliers, demands of downstream customers, behaviors of competitors, complementary manufacturers, existing relevant industrial knowledge, creativity, innovation and creation of resource integration. Pre- 
vious experience in a specific industry helps entrepreneurs identify entrepreneurial opportunities. The more experience and knowledge a new farmer has in relevant agricultural advantageous industries, the easier it will be to find and grasp the entrepreneurial opportunities in this field, so as to start a successful business.

Secondly, the innovation and creativity of members of the new farmer social network have an impact on the perception and identification of entrepreneurial opportunities. The essence of entrepreneurship is innovation, creation and the creative integration of resources to generate value. New farmers' entrepreneurial fields include rural ecological recycling industry, life service industry, health industry, folk education industry, rural tourism industry and so on. New farmers' entrepreneurial opportunities come from obtaining relevant products of value (value to customers in the target market segment) with different attributes (compared with competitors' product attributes), that is, to improve the cost performance of products and services. The identification process of entrepreneurial opportunities for new farmers also requires the creation of new value, and the final formation of new products, new services, new raw materials, and new ways of organization, which is a constantly repeated creative thinking process. When members of the new farmers' social network come up with creative solutions to existing products or services, new ideas/innovations can be developed in ways that improve the cost performance, which is the discovery of entrepreneurial opportunities. Without a certain degree of innovation/creative thinking ability, it is difficult to grasp the entrepreneurial opportunities even if the high-value information is acquired and the new needs of customers are clarified.

Thirdly, the entrepreneurial environment cognition of the social network members of new farmers has an impact on the perception and identification of entrepreneurial opportunities. The entrepreneurial environment of new farmers will have great influence on the identification of their entrepreneurial opportunities. The entrepreneurial environment of new farmers is a combination of many factors in the entrepreneurial process, including the overall rural population environment, technological environment, natural environment, market environment, entrepreneurial values, etc. For example, the policy tendency of rural revitalization, the change of people's life style, and the fairness of market competition environment will all have a great impact on the identification of entrepreneurial opportunities, and even affect the entrepreneurial enthusiasm of new farmers.

Finally, the cross-city, cross-region or cross-country business observation of the members of the new farmer's social network has an impact on the discovery and identification of entrepreneurial opportunities. When there are differences in business models between cities, regions or countries, product types and prices of agricultural industrial chains, and technological differences, new farmers will find new business models of entrepreneurial opportunities when they travel and observe. 


\section{Conclusion}

The new farmer's entrepreneurship begins with his identification of entrepreneurial opportunities. Identifying entrepreneurial opportunities is a process of repeated thinking and exploration and the transformation of ideas. It is a process of constant adjustment, repetition and balance. With the cooperation of social capital, the potential expected value of the opportunity and the ability of the new farmer entrepreneur are repeatedly weighed, and the entrepreneur's strategic positioning of the opportunity is becoming more and more explicit.

The identification of entrepreneurial opportunity is the starting point and the key problem of new farmers' entrepreneurship. Opportunity is a variable on the timeline, not always available. A good entrepreneurial opportunity is attractive, durable, and timely, and it is embedded in a product (service) that creates or adds value to its users. Is there enough time for new farmers to seize an opportunity in the process of starting a business? The entrepreneurial opportunity is usually a moving target, but whether the new farmer can identify the target and seize the opportunity depends on the new farmer's social capital accumulation, technical ability, the action of competitors, etc.

From the perspective of theoretical mechanism, the relational dimension, structural dimension and cognitive dimension of social capital have an impact on the identification of entrepreneurial opportunities for new farmers. From the perspective of relationship dimension, if the social relation network of new farmers is a primary relation network based on blood relationship and geographical relationship, that is, lacking in-depth social networks and "weak connections", it will hinder the opportunity identification and entrepreneurial development of new farmers to a certain extent. In terms of relationship and cognitive dimensions, from the perspective of different types of new farmers, cross-industry entrepreneurial new farmers have rich entrepreneurial experience, many social identities and relatively wide social relationship network, and their social capital stock is often larger than that of college students and migrant workers returning to their hometowns. The college students, as the new farmers, have a higher degree of grasp of the national preferential policies, and they have some advantages in the relationship network construction with the government. In the structural dimension, the social network scale and network density of new farmers affect the discovery and identification of entrepreneurial opportunities. The more holes in the structure are filled by the network of new farmer entrepreneurs, the more likely they are to identify entrepreneurial opportunities.

Social capital needs to be nurtured to help new farmers successfully identify entrepreneurial opportunities. The cultivation of social capital for new farmers is a long-term and complex systematic project, which requires the joint efforts of the governments and civil society organizations (CSOs), and it is impossible to achieve good results relying solely on the government or CSO. To be specific, it should be carried out from three aspects: constructing social credit system, perfecting social norms and developing participation network. Having good per- 
sonal credit is the premise of cultivating social capital, perfect social norms is the basis, and developing participation network is the foundation. Governments at all levels should actively build social network platforms to guide new farmers, individuals with more entrepreneurial resources, associations and other social groups to establish and operate social networks. A diversified and widely distributed network of social relations should gradually be formed to help new farmers identify entrepreneurial opportunities and thus stimulate their entrepreneurial vitality.

\section{Supporting Funds}

1) The Employment Supports for Land-expropriated Farmers of Daxing District in Beijing from the Perspective of Three-dimensional Capital, Beijing Social Science Foundation Research Base Project (16JDSRC008). 2) The Bilingual Teaching Reform and Practice-Based on the Model of Outcome-based Education, Key Project of Education and Teaching Reform and Research, Beijing Institute of Petrochemical Technology (ZD20200409). 3) Research on the Influencing Mechanism of Three-dimensional Social Capital on the Identification of Entrepreneurial Opportunity for New Farmers, 2020 Beijing University Students Scientific Research Training Program (URT: 2020J00209).

\section{Conflicts of Interest}

The authors declare no conflicts of interest regarding the publication of this paper.

\section{References}

Gao, J., Zhang, Y., \& He, C. (2013). An Empirical Study on the Influence of Initial Social Capital on Entrepreneurial Opportunity Identification of Farmers. Journal of Huazhong Agricultural University (Social Science Edition), 1, 47-52.

Granovetter, M. (1973). The Strength of Weak Ties. American Journal of Sociology, 6, 1360-1380. https://doi.org/10.1086/225469

Guo, H., \& Ding, G. (2012). Social Capital, Prior Knowledge and Identification of Entrepreneurial Opportunities for Farmers. Journal of South China Agricultural University (Social Science Edition), 3, 78-85.

Guo, Y., \& Tan, Y. (2016). Factors Influencing the Growth of New Farmers and Policy Path. Agricultural Economy, 4, 68-69.

Nahapiet, J., \& Ghoshal, S. (1998). Social Capital, Intellectual Capital and the Organizational Advantage. Academy of Management Review, 2, 242-266.

https://doi.org/10.5465/amr.1998.533225

Shu, R. (2012). A Study on the Influence of Social Capital on the Identification and Development of Entrepreneurial Opportunities. Changsha: Central South University.

Tang, D. (2020). Connotation, Source and Identification of Entrepreneurial Opportunities. Cooperative Economics and Technology, 1, 148-151.

Wang, Y., Wan, Y., \& Liu, Z. (2017). Research on the Relationship between Three- Dimensional Social Capital and Entrepreneurial Opportunity Identification Characteristics-An Empirical Analysis Based on 336 Questionnaires in the "Middle Triangle". 
Industrial Technology and Economy, 1, 41-50.

Yan, A., \& Jiang, H. (2018). Exploration on the Coupling and Coordinated Development of Rural Finance and New Farmer Entrepreneurship. Journal of Huaihua University, 7, 28-30.

Yan, A., \& Jiang, H. (2019). Analysis of Entrepreneurship of New Farmers from the Perspective of Agricultural Supply-Side Reform-A Case Study of Anhui Province. Journal of Huaihua University, 10, 71-74.

Zhang, H. (2016). Investigation on the Development of New Farmers in the Context of Agricultural Supply-Side Structural Reform. China Rural Economy, 4, 2-11.

Zhou, L. (2014). The Family Social Capital, Prior Experiences, and Identification of Entrepreneurial Opportunities-An Empirical Study from Microenterprises. Science and Technology Progress and Countermeasures, 10, 87-91.

Zhu, J., \& Hu, W. (2015). Research on the Relationship between Domestic and Foreign Capital and the Entrepreneurial Performance of Returnees. Science and Technology Management Research, 20, 127-132.

Zhu, L. (2013). Research on the Influence of Social Capital of Small and Micro Business Entrepreneurs on Entrepreneurial Opportunity Identification Behaviors. Tianjin: Tianjin University of Finance and Economics. 